\title{
Is it Worth Implanting TVA/TOA Adjustable Tapes?
}

\author{
Romero-Maroto J*, Gomez-Perez L, Lopez-Lopez A and Laura Martínez-Cayuelas \\ Department of Urology, University Hospital San Juan, Spain
}

Submission: February 14, 2017; Published: February 20, 2017

*Corresponding author: Romero Maroto J, Department of Urology, University Hospital San Juan, Spain, Email: jromeroma@coma.es

Abbreviations: TVT: Trans Vaginal Tape; TOT: Trans-Obturator Vaginal Tape

News

Sub-urethral meshes are considered the current standard in the treatment of female stress urinary incontinence [1].

The trans vaginal tape (TVT) procedure cures urinary stress incontinence in a high percentage of cases. However, approximately $15 \%$ of patients still suffer a certain level of incontinence, and the procedure also leads to post-operative voiding dysfunction in a relatively important number of patients [2-3]. The trans-obturator vaginal tape (TOT) technique was introduced with the aim of voiding visceral and vascular injuries and to eliminate the obstructive component of tension free vaginal tape (TVT).

TOT procedure cure rate varying from 51\%-95\%, depending on the definition used for success, the outcomes instruments, and discrepancies in studied population. Complete urinary retention has occurred from $0 \%$ to $13.3 \%$ [2]. After TOT procedure and tape sectioning or tape adjustment were necessary in up to $5 \%$ of the cases $[4,5]$.

It seems that there is a delicate balance after sub-urethral tape implant between incontinence, continence, and obstruction, and it is difficult to calculate the correct degree of tension to be applied during surgery. When the tape is too loose, incontinence persists. On the other hand, when the tape is too tight, urinary obstruction is produced.

Sub-urethral adjustable meshes TVA and TOA (AMI GmbH, Austria) [6] were developed in order to improve the results of conventional meshes.

The implantation of an adjustable mesh theoretically has certain advantages, makes it possible to correct the possible persistence of post-operative incontinence or obstruction several days after surgery. Excellent short, medium and longterm results have been published with this technique [610]. However, the benefits of adjustable tapes has not been established as there are not randomized comparative studies between adjustable and non-adjustable meshes.

The only existing comparative study, non-randomized, between adjustable and non-adjustable mesh was conducted by Youn, et al. [9] with the trans-obturator mesh. Healing and satisfaction were $90 \%$ and $95 \%$ with the TOA mesh versus 85 and $85 \%$ with TOT. One patient required increasing tension and four decrease it in the TOA group. Eight patients showed obstruction in the TOT group and three of them needed a urethrolysis. The urine residue was significantly lower in the TOA group.

The comparison among different reports is difficult due to the different criteria used in the assessment, the different definition used for success, the different out come instruments, and discrepancies in studied population.

The adjustable tape objective success. However, despite the differences is comparable and even superior to that of published studies. The adjustable retropubic sub-urethral mesh appear to be quite effective with an $87.5 \%$ objective success at 10 years, showing no significant difference with the result at 1 year (90.6\%) [10].

The subjective success is again difficult to compare because of the different definitions of it. The subjective success is not defined by a single variable but by several inter related that gives us a true picture of the situation and will depend, in turn, on the expectations of patients. A subjective success defined by a questionnaire with three situations, cure, improvement or failure may have more to do with the satisfaction obtained. However, when satisfaction is considered, adjustable tape results are comparable to those published [11-12].

Eighty seven percent of patients had good quality of life and were satisfied 1 year after surgery in a TVA study [10]. Seventy eight percent responded the same at 10 years. Urgency, 
either as urge incontinence or as a component of mixed urinary incontinence, is the main cause of the difference between 1 and 10 years result [10].

In line with this adjustable tape experience, Svenningsen [12] reported a significant progressive decrease of women answering being very satisfied and Liapis found $12.3 \%$ of urgency after a year and $19.6 \%$ at 7 years. The role that the aging process plays in this decline of subjective success is difficult to establish.

No voiding dysfunction has been reported in patients with adjustable tape. Unlike this, many series of non adjustable tape show a certain percentage of patients signs or symptoms of voiding dysfunction, urinary retention after surgery, urinary difficulty, urethrotomy, urethral dilatation or section of the mesh. The possibility of adjusting the tension of the mesh postoperatively appears to prevent the occurrence of obstructive voiding dysfunction.

As complications or erosions or infections are concerned, it seems not to be any difference between adjustable and nonadjustable tapes. External threads and tension adjusters, they did not seem to increase the risk of infection.

Despite these results, there is no quality evidence to point its superiority and the benefits of adjustable tapes has not been established as there are not comparative, randomized, studies between TVA/TOA adjustable tapes and non-adjustable tapes.

\section{References}

1. Novara G, Artibani W, Barber MD, Chapple CR, Costantini E, et al. (2010) Updated systematic review and meta-analysis of the comparative data on colpo-suspensions, pubovaginal slings, and mid urethral tapes in the surgical treatment of female stress urinary incontinence. Eur Urol 58(2): 218-238.

2. Hualde A, Jiménez J, Sarmiento C, Pinos Paul M, De Pablo Cárdenas A, et al. (2006) Nuestra experiencia a cinco años y medio en TVT. Actas Urol Esp 30(2): 181-185.
3. Doo Ch, Hong B, Chung BJ, Kim JY, Jung HC, et al. (2006) Five-year outcomes of the tension-free vaginal tape procedure for treatment of female stress urinary incontinence. Eur Urol 50(2): 333-338.

4. Porena M, Costantini E, Frea B, Giannantoni A, Ranzoni S, et al. (2007) Tension-free vaginal tape versus trans- obturator tape as surgery for stress urinary incontinence: results of a multi-centre randomised trial. Eur Urol 5295: 1481-1490.

5. Morey AF, Medendorp AR, Noller MW, Mora RV, Shandera KC, et al. (2006) Trans-obturator versus trans-abdominal mid urethral sling: a multi-institutional comparison of obstructive voiding complications. J Urol 175(3 pt 1): 1014-1017.

6. Romero Maroto J, Ortiz Gorraiz M, Prieto Chaparro L, Pacheco Bru JJ, Miralles Bueno JJ (2008) Trans vaginal adjustable tape: an adjustable mesh for surgical treatment of female stress urinary incontinence. Int Urogynecol J Pelvic Floor Dysfunct 19(8): 1109-1116.

7. Schmid C, Bloch E, Amann E, Mueller MD, Kuhn A (2010) An adjustable sling in the management of recurrent urodynamic stress incontinence after previous failed midurethral tape. Neurourol Urodyn 29(4): 573577.

8. Costantini S, Nadalini C, Esposito F, Alessandri F, Valenzano MM, et al. (2010) Trans obturator adjustable tape (TOA) in female stress urinary incontinence associated with low maximal urethral closure pressure. Arch Gynecol Obstet 282(3): 277-284.

9. Youn CS, Shin JH, Na YG (2010) Comparison of TOA and TOT for treating female stress urinary incontinence: short-term outcomes. Korean J Urol 51(8): 544-549.

10. Romero-Maroto J, Pérez-Seoane H, Gómez-Perez L, Pérez-Tomás C, Pacheco-Bru JJ, López-López A (2016) Is the adjustable TVA mesh effective for the long-term treatment of female stress incontinence . Actas Urol Esp 41(1): 55-61.

11. Olsson I, Abrahamsson AK, Kroon UB (2010) Long-term efficacy of the tension-free vaginal tape procedure for the treatment of urinary incontinence: a retrospective follow-up 11.5 years post- operatively. Int Urogynecol J 21(6): 679-683.

12. Svenningsen R, Staff AC, Schiotz HA, Western K, Kulseng- Hanssen S (2013) Long-term follow-up of the retropubic tension-free vaginal tape procedure. Int Urogynecol J 24(8): 1271-1278.

\section{Your next submission with Juniper Publishers} will reach you the below assets

- Quality Editorial service

- Swift Peer Review

- Reprints availability

- E-prints Service

- Manuscript Podcast for convenient understanding

- Global attainment for your research

- Manuscript accessibility in different formats

( Pdf, E-pub, Full Text, Audio)

- Unceasing customer service

Track the below URL for one-step submission https://juniperpublishers.com/online-submission.php 